\title{
Detection of Helicobacter pylori infection of the gastric mucosa by measurement of gastric aspirate ammonium and urea concentrations
}

\author{
W D Neithercut, A Milne, R S Chittajallu, A M El Nujumi, K E L McColl
}

\begin{abstract}
Helicobacter pylori possesses unusually high urease activity that lowers the urea concentration and raises the ammonium concentration of the gastric juice in infected people. The value of measuring urea and ammonium concentrations in gastric juice obtained during upper gastrointestinal endoscopy as a means of diagnosing the presence and eradication of the infection was assessed. Twenty four subjects with the infection and 14 in whom it had been eradicated were examined. Their $H$ pylori status was confirmed by antral biopsy and ${ }^{14} \mathrm{C}$ urea breath test. The median (range) gastric juice urea concentration in infected subjects was $0.8 \mathrm{mmol} / 1(0.5-2.9 \mathrm{mmol} / \mathrm{l})$, which was lower than that in the uninfected subjects $\left(2 \cdot 1 \mathrm{mmol} / \mathrm{l}^{\prime}(1 \cdot 0-3.7 \mathrm{mmol} / \mathrm{l})\right)$ $(\mathbf{p}<0.001)$. The median gastric juice ammonium concentration in infected subjects was $3.4 \mathrm{mmol} / \mathrm{l}(1.0-13.0 \mathrm{mmol} / \mathrm{l})$, which was higher than that in the uninfected subjects $(0.64$ $\mathrm{mmol} / \mathrm{l}(0.02-1.4 \mathrm{mmol} / \mathrm{l}))(\mathrm{p}<0.001)$. Though the two groups overlapped in respect of their urea and ammonium concentrations, they were completely different when the urea: ammonium ratios were calculated - the ratios ranged from 0.04-0.7 (median 0.26) and from 1.1-113 (median 3.4) in infected and uninfected subjects respectively $(p<0 \cdot 001)$. Treatment with $\mathrm{H}_{2}$ antagonists did not change the concentrations of urea and ammonium or their ratio in gastric juice. Measurement of the urea:ammonium ratio in aspirated gastric juice obtained during routine upper gastrointestinal endoscopy may provide a rapid method of detecting $\boldsymbol{H}$ pylori infection and of confirming its eradication.
\end{abstract}

Helicobacter pylori infection of the gastric antral mucosa is present in the vast majority of duodenal ulcer patients and its eradication reduces appreciably the ulcer relapse rate. ${ }^{\prime}$ The ability to detect the infection and confirm its eradication is likely to become increasingly important in the management of patients with duodenal ulcer disease.

$H$ pylori has remarkably high urease activity ${ }^{23}$ which provides a useful means of detecting its presence. At present there are two widely used methods of diagnosing $H$ pylori infection based upon its urease activity. One involves the measurement of the rate of ammonia formation after incubation of an antral biopsy specimen in a urea containing medium. ${ }^{+}$There are several variations of this method and most detect the ammonia formed by means of the change in colour of a $\mathrm{pH}$ indicator such as phenol red. The time from incubation of the biopsy specimen until the change in colour occurs, varies from three to 24 hours. ${ }^{4}$ The second method involves the oral administration of ${ }^{14} \mathrm{C}$ or ${ }^{13} \mathrm{C}$ labelled urea and subsequent analysis of labelled $\mathrm{CO}_{2}$ excreted in the breath. ${ }^{5-7}$ This test takes one to two hours to perform and the final result is not usually available until the next day at the earliest.

The high urease activity of the organism results in raised gastric juice ammonium ion concentrations and reduced gastric juice urea concentrations. ${ }^{89} \mathrm{We}$ have assessed the value of measuring the concentrations of urea and ammonium in gastric aspirate obtained during diagnostic endoscopy as this could provide the most rapid means of diagnosing the presence and confirming the eradication of $H$ pylori infection.

\section{Patients and methods}

Twenty seven patients ( 21 men, age range 18-64 years) with a history of endoscopically proved duodenal ulceration were examined. Two of them were taking ranitidine but none had been prescribed omeprazole. All had normal renal function. Twelve were examined on one occasion only, having never received any anti- $H$ pylori treatment. Twelve were examined before and one month after completing a four week course of tripotassium dicitrato bismuthate $(120 \mathrm{mg}$ tid), metronidazole (400 mg tid), and amoxycillin (250 mg tid). Three patients were examined only one month after the same treatment. At each time point examined, an upper gastrointestinal endoscopy and ${ }^{14} \mathrm{C}$ urea breath test were performed. All the patients had fasted for 16 hours before endoscopy.

During the endoscopy and just after entering the stomach, $2 \mathrm{ml}$ of gastric juice were aspirated through the suction channel of the endoscope and collected in a trap inserted in the suction line. Routine inspection of the upper gastrointestinal tract was then performed and after this an antral biopsy specimen was obtained for histological examination. The specimen was fixed in formalin before staining with haematoxylin and eosin. The severity of histological gastritis was scored as described by Rauws et $a l^{10}$ and the presence of $H$ pylori noted.

The gastric juice samples were stored frozen at $-20^{\circ} \mathrm{C}$ until analysed. Before analysis, the samples were centrifuged at $3000 \mathrm{~g}$ for 10 minutes to remove the mucus. The concentration of ammonium was measured in the supernatant after dilution in $0.2 \mathrm{~mol} / 1$ phosphate buffer $\mathrm{pH} 7.4$ using an enzymatic method (Sigma Chemical Co, Dorset, UK) adapted for 
TABLE I Area under the breath test curve before and after eradication of $\mathrm{H}$ pylori

\begin{tabular}{|c|c|c|c|c|c|}
\hline \multirow[b]{2}{*}{ Group } & \multicolumn{4}{|c|}{ Area under breath test curve (median (range) $)\left(\%\right.$ dose $\left./ \mathrm{mmol} \mathrm{CO}_{2} \times \mathrm{kg} \times \min \right)$} & \multirow{2}{*}{$\begin{array}{l}\text { Peak of } 10 / 20 \text { min breath } \\
\text { test result }(\% \text { dose } / \mathrm{mmol} \\
\left.\mathrm{CO}_{2} \times k g \times 100\right)\end{array}$} \\
\hline & $0-30 \min$ & $0-40 \min$ & $0-60 \min$ & $0-120 \min$ & \\
\hline $\begin{array}{l}\text { Pre-eradication of } H \text { pylori }(\mathrm{n}=24) \\
\text { Post-eradication of } H \text { pylori }(\mathrm{n}=14)\end{array}$ & $\begin{array}{l}25(6-42) \\
0 \cdot 6(0 \cdot 1-1 \cdot 1)\end{array}$ & $\begin{array}{l}41(12-69) \\
0 \cdot 7(0 \cdot 3-2 \cdot 5)\end{array}$ & $\begin{array}{l}76(23-127) \\
1 \cdot 7(0 \cdot 8-7 \cdot 2)\end{array}$ & $\begin{array}{l}152(63-267) \\
5 \cdot 0(3 \cdot 0-18 \cdot 0)\end{array}$ & $\begin{array}{r}137(39-225) \\
2 \cdot 6(0-5 \cdot 1)\end{array}$ \\
\hline
\end{tabular}

the Cobas Bio (Roche, Welwyn Garden City, UK). Studies were performed to assess the reliability of this method for determining ammonium concentrations in gastric juice. Urea concentrations were measured by a urease enzymatic method (SMAC I, Technicon, Basingstoke, UK).

Within five days of each endoscopic examination, ${ }^{14} \mathrm{C}$ urea breath test was performed. After a 14 hour overnight fast, the patients drank 240 $\mathrm{ml}$ of Ensure Plus (Abbott, Maidenhead, UK) to delay gastric emptying, followed by $0.4 \mathrm{MBq}{ }^{14} \mathrm{C}$ urea in $20 \mathrm{ml}$ water. Samples of breath $\mathrm{CO}_{2}$ were collected every 10 minutes for 30 minutes before administration of the isotope and for 120 minutes afterwards. The appearance of ${ }^{14} \mathrm{C}$ labelled $\mathrm{CO}_{2}$ in the breath samples was followed by liquid scintillation counting. The area under the curve of the breath test was calculated using the trapezoid rule for the time period 0-30 minutes, $0-40$ minutes, $0-60$ minutes, and 0-120 minutes of the test.

THE EFFECT OF $\mathrm{H}_{2}$ RECEPTOR ANTAGONISTS A further study was performed in an additional 10 patients (three $H$ pylori positive, seven $H$ pylori negative) to investigate the effect of $\mathrm{H}_{2}$ receptor antagonist treatment on the concentrations of urea and ammonium and their ratio in gastric juice. A fasting sample of gastric juice was obtained from each patient before and after a one week course of ranitidine ( $300 \mathrm{mg}$ nocte). The second sample of gastric juice was obtained within 14 hours of the last dose of ranitidine.

Statistical significance was tested by the Mann-Whitney U test. The study was approved by the Western Infirmary Ethical Committee and each patient gave written, informed consent.

\section{Results}

In the 24 duodenal ulcer patients who had not received anti- $H$ pylori treatment, the organism was present in each on examination of their antral biopsy specimen. In each of these patients antral gastritis was also present and their median score for severity of gastritis was 5 (range 2-8). In 14 of the 15 patients examined one month after completing a course of anti- $H$ pylori therapy, no $H$ pylori like organisms were identified and none had gastritis scores greater than 1 . In one patient the treatment failed to eradicate the infection and the bacterium was still present on the mucosa and associated with persisting antral gastritis with a severity score of 5 . This patient's pretreatment aspirate ammonium and urea concentrations were $2.5 \mathrm{mmol} / \mathrm{l}$ and $0.7 \mathrm{mmol} / \mathrm{l}$ respectively, while after treatment they were $2 \cdot 7$ $\mathrm{mmol} / \mathrm{l}$ and $0.7 \mathrm{mmol} / \mathrm{l}$ respectively.

Analysis of the area under the breath test curve two hours after isotope administration showed clear separation of the patients with histological evidence of eradication of the infection from those with evidence of the infection and who had never received anti- $H$ pylori treatment (Table I).
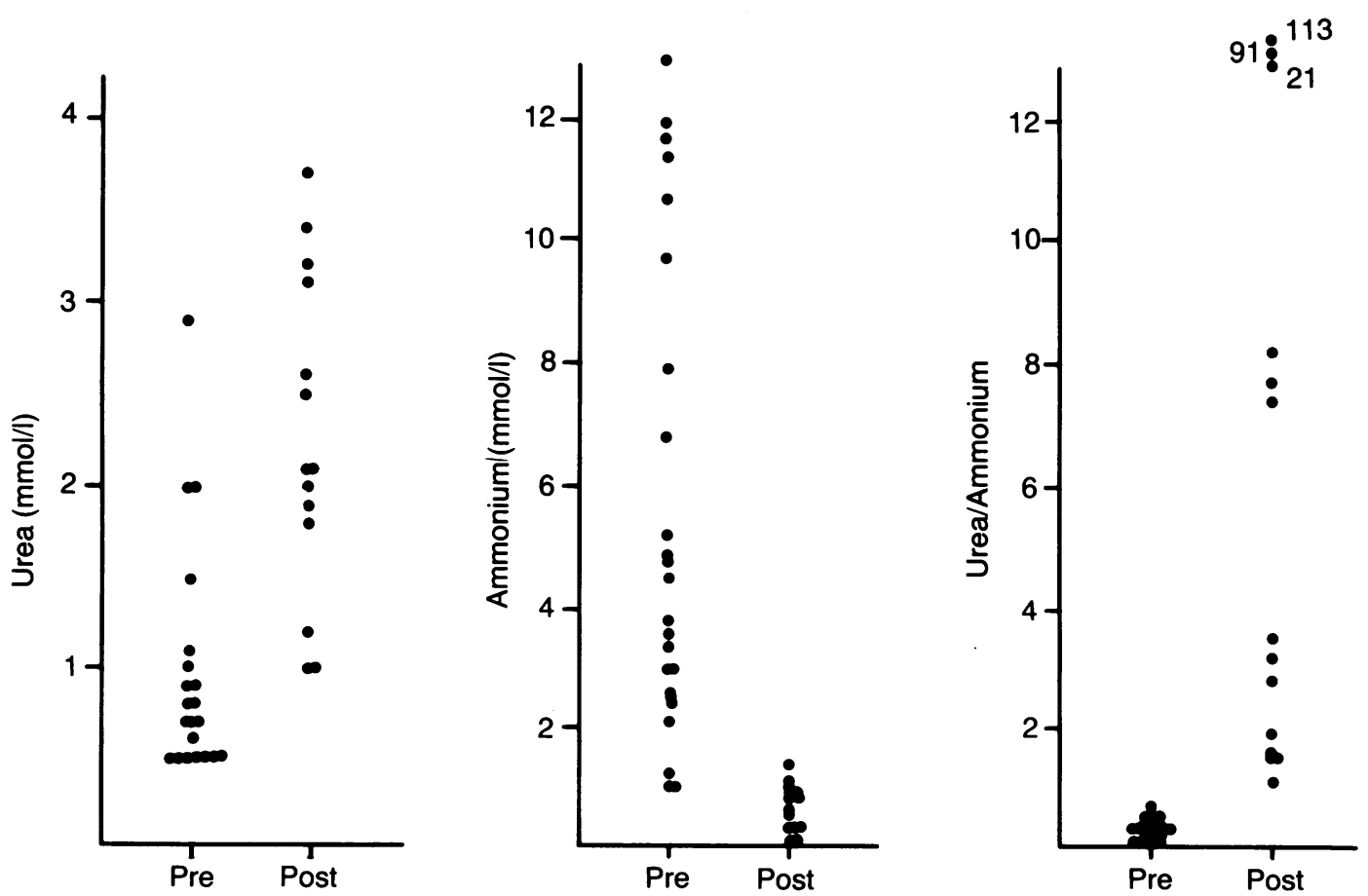

Figure 1: Urea and ammonium concentrations (mmol/l) and the urea:ammonium ratio in gastric juice samples from subjects before and after eradication of Helicobacter pylori. 


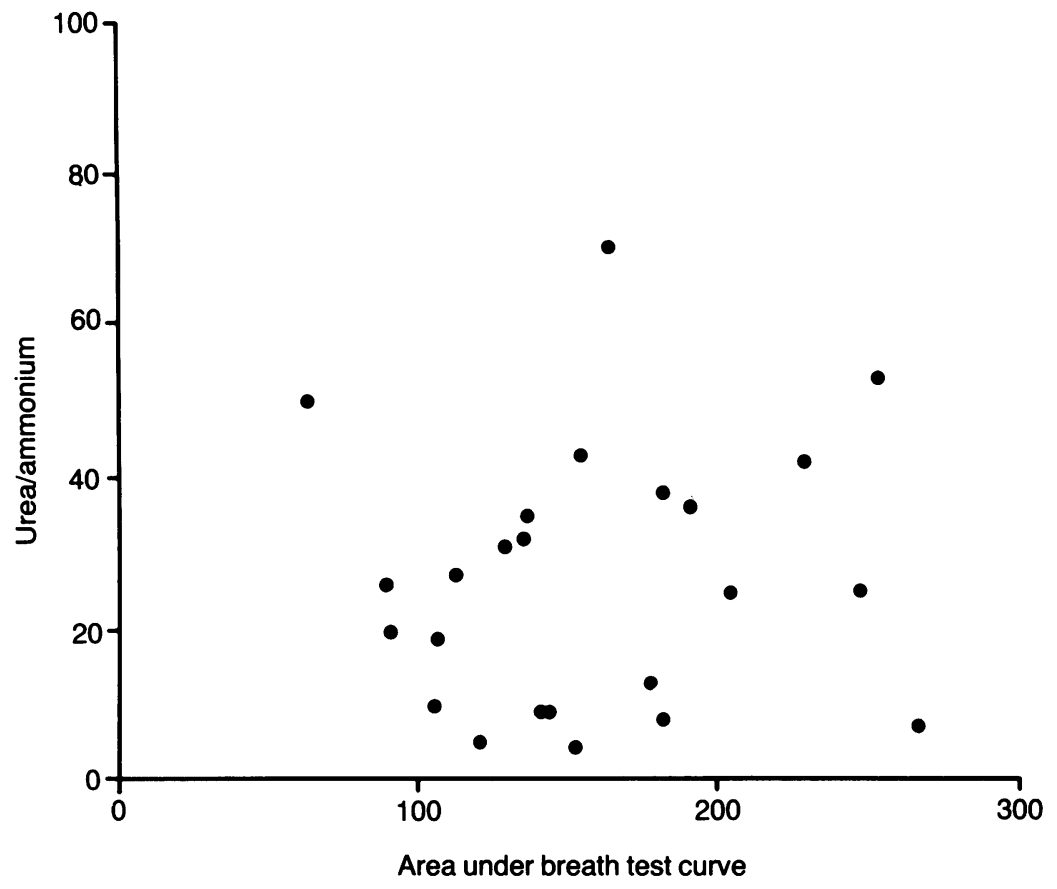

Figure 2: Correlation of the area under the 120 minute breath test curve (\% dose/mmol $\mathrm{CO}_{2} \mathrm{~kg}$ body weight $\times$ min) with the urea:ammonium ratio in gastric juice $(r=0.004)$.

The values in the former were all less than 20 (range, 3-18) and in the latter all greater than 60 (range, 63-267). In the one patient with histological evidence of failure of eradication the value was 114 before treatment and 90 after treatment. She was therefore included only as a positive for $H$ pylori in the further analysis. There was also complete separation of the two groups with the calculated area under the curve for the first 30 minutes, 40 minutes, and 60 minutes of the breath test. Even the higher single value of either of the 10 minute or 20 minute breath test results was also found to separate the patients clearly into the two groups, indicating that a shortened 20 minute breath test could be as useful as the complete two hour test.

The method of ammonium measurement in the gastric juice samples was assessed. The intra-assay coefficient of variation at $10 \mathrm{mmol} / \mathrm{l}$ ammonium concentration was $1.0 \%$ while the inter-assay coefficient of variation was $2 \cdot 0 \%$. Using samples from patients, the intra-assay coefficient of variation, including dilution, varied from $8.5 \%$ at an ammonium concentration of $2.3 \mathrm{mmol} / \mathrm{l}$ to $1 \%$ at an ammonium concentration of $13.0 \mathrm{mmol} / \mathrm{l}$. The measured

TABLE II Effect of seven days' treatment with ranitidine (300 mg nocte) on the concentrations of urea and ammonium and their ratio in gastric juice

\begin{tabular}{|c|c|c|c|c|c|c|}
\hline & \multicolumn{3}{|l|}{ Pretreatment } & \multicolumn{3}{|c|}{ During ranitidine treatment } \\
\hline & Ammonium & Urea & Ratio & Ammonium & Urea & Ratio \\
\hline \multicolumn{7}{|l|}{ H pylori - ve patients } \\
\hline 1 & $2 \cdot 0$ & $2 \cdot 9$ & $1 \cdot 4$ & 1.9 & $2 \cdot 6$ & $1 \cdot 3$ \\
\hline 2 & $2 \cdot 2$ & $3 \cdot 1$ & $1 \cdot 4$ & $2 \cdot 9$ & $2 \cdot 6$ & 0.9 \\
\hline 3 & $2 \cdot 0$ & $4 \cdot 3$ & $2 \cdot 1$ & $2 \cdot 5$ & $3 \cdot 0$ & $1 \cdot 2$ \\
\hline 4 & 0.8 & $2 \cdot 2$ & $2 \cdot 6$ & $2 \cdot 0$ & $2 \cdot 7$ & $1 \cdot 3$ \\
\hline 5 & $1 \cdot 6$ & 2.5 & 1.6 & $2 \cdot 8$ & $3 \cdot 0$ & $1 \cdot 1$ \\
\hline 6 & $1 \cdot 4$ & $2 \cdot 0$ & $1 \cdot 4$ & $1 \cdot 2$ & 1.9 & $1 \cdot 6$ \\
\hline 7 & $2 \cdot 2$ & $2 \cdot 1$ & 0.9 & $2 \cdot \overline{5}$ & $2 \cdot 6$ & $1 \cdot 0$ \\
\hline \multicolumn{7}{|l|}{ H pylori + ve patients } \\
\hline $\begin{array}{l}1 \\
2\end{array}$ & $\begin{array}{l}6 \cdot 1 \\
8 \cdot 8\end{array}$ & $1 \cdot 2$ & $\begin{array}{l}0 \cdot 2 \\
0.2\end{array}$ & $\begin{array}{l}5 \cdot 7 \\
5 \cdot 2\end{array}$ & $\begin{array}{l}1.4 \\
1.6\end{array}$ & $\begin{array}{l}0.2 \\
0.3\end{array}$ \\
\hline 3 & $\begin{array}{l}0.0 \\
7 \cdot 2\end{array}$ & 0.6 & 0.1 & $8 \cdot 4$ & $0 \cdot 2$ & $0 \cdot 1$ \\
\hline
\end{tabular}

ammonium concentration in patients' samples was linear with serial dilution. The detection limit for the assay was $30 \mu \mathrm{mol} / \mathrm{l}$. Samples kept in a freezer at $-20^{\circ} \mathrm{C}$ also showed no significant change in ammonium concentration over a 21 day period.

The median (range) gastric juice urea concentration was $0.8 \mathrm{mmol} / \mathrm{l}(0.5-2.9 \mathrm{mmol} / \mathrm{l})$ in those with the infection compared with $2 \cdot 1 \mathrm{mmol} / \mathrm{l}$ $(1.0-3.7 \mathrm{mmol} / \mathrm{l})$ in the patients in whom it had been eradicated $(p<0.001)$ (Fig 1). The median (range) gastric juice ammonium concentration was $3.4 \mathrm{mmol} / \mathrm{l}(1.0-13.0 \mathrm{mmol} / \mathrm{l})$ in infected subjects and $0.64 \mathrm{mmol} / \mathrm{l}(0.02-1.4 \mathrm{mmol} / \mathrm{l})$ after eradication ( $p<0.001)$ (Fig 1). Though there was considerable overlap between the two groups in respect of their urea and ammonium concentrations there was complete separation of the groups when the urea:ammonium ratio was considered (Fig 1). The median ratio in gastric juice of infected subjects was $0.26(0.04-0.7)$ compared with $3.4(1 \cdot 1-113)$ in those cleared of the infection $(\mathrm{p}<0.001)$. Thus, all subjects with $H$ pylori infection had a urea:ammonium ratio of less than 0.8 and all those in whom the infection had been eradicated had a ratio of more than $1 \cdot 0$.

In those with the infection, there was no correlation of the area under the two hour breath test values curve and the gastric urea concentration, ammonium concentration, or urea: ammonium ratio (Fig 2).

\section{EFFECT OF $\mathrm{H}_{2}$ RECEPTOR ANTAGONISTS}

In the 10 patients studied before and after seven days' ranitidine treatment, there was no change in the gastric juice concentrations of urea and ammonium or in their ratio (Table II). Taking urea:ammonium ratios of 0.8 or below as indicative of infection, the $\mathrm{H}_{2}$ antagonist treatment did not change the $H$ pylori classification of any of the subjects.

\section{Discussion}

The unusually high urease activity of $H$ pylori has been used to detect the presence of the organism in the gastric antral mucosa in several different ways. The ${ }^{14} \mathrm{C}$ urea breath test relies on the detection of exhaled radiolabelled $\mathrm{CO}_{2}$ formed during the hydrolysis of urea. This test is reproducible and is regarded as a sensitive method of detecting infection of the antral mucosa with the organism. ${ }^{56}$ However, it does have several disadvantages. The collection of the breath samples takes two hours to complete using the standard protocol, although a shortened breath test relying on a 40 minute breath sample has been proposed. "Our data indicate that the higher value of the 10 minute and 20 minute values can distinguish those with the infection from those in whom it has been eradicated. This would allow the test to be performed within 30 minutes. Unfortunately, analysis of the breath samples is also time consuming making it difficult to obtain the result on the same day. The breath test also involves the administration of a small dose of radioactivity which might make it unsuitable for the investigation of children and premenopausal women and 
for multiple studies. The ${ }^{13} \mathrm{C}$ urea breath test eliminates the risk of administering a radioisotope but because mass spectrometry is required for the detection of ${ }^{13} \mathrm{C} \mathrm{CO}_{2}$ is unlikely to be introduced into general use. ${ }^{7}$

The rapid urease (CLO-test) uses the change in colour of a $\mathrm{pH}$ indicator dye in response to the urease activity in a biopsy sample inserted into the gel to detect the organism. The colour change in the gel usually takes three hours to complete, but may take up to 24 hours. The disadvantages of this test are that an antral biopsy specimen is required and the investigator must also remember to read the gel at the correct time. Again, one cannot rely on having the result on the same day as the test is performed.

The urease activity of the organism results in low gastric juice urea concentrations and raised gastric juice ammonium concentrations. ${ }^{89}$ Our study has shown that the urea:ammonium ratio in gastric juice clearly separates patients with $H$ pylori infection from those in whom it has been eradicated. The discriminating ability of this ratio can be explained by the inverse effect that the organism's urease activity exerts on urea and ammonium concentrations in gastric juice.

In those with the infection, there was no correlation between the urease activity as assessed by the urea breath test and the ratio of urea:ammonium concentrations in gastric juice. This absence of correlation may be explained as follows. The ${ }^{14} \mathrm{C}$ urea breath test is a dynamic test, measuring the response of the enzyme to a urea load, while the urea:ammonium ratio is a measure of basal $H$ pylori urease activity. The rate of ammonia production in infected subjects may be mainly dependent on the availability of urea. We have previously found that intragastric infusion of urea results in a noticeable increase in the ammonium concentration in gastric juice, indicating that it is substrate availability that determines ammonium production. ${ }^{9}$ Finally, the concentration of urea in gastric juice of patients with the organism may, on occasion, be below the detection limit for accurate determination.

The analysis of the concentrations of ammonium and urea in gastric juice could be com- pleted more rapidly than either the urea breath test or the rapid urease test. With modern analytical equipment the measurement of their concentrations in a sample of gastric juice obtained at endoscopic examination might be completed within 10 to 15 minutes. Our studies indicate that dosing with the $\mathrm{H}_{2}$ antagonist ranitidine on the evening before the endoscopic examination does not alter the discriminating value of the urea:ammonium ratio or indeed the concentrations of urea and ammonium in gastric juice.

In conclusion, measurement of the ratio of the concentrations of urea and ammonium in gastric juice samples from fasted subjects provides a simple method of determining the $H$ pylori status of duodenal ulcer patients.

We are grateful to the Department of Nuclear Medicine at the Western Infirmary for preparing the ${ }^{1+} \mathrm{C}$ urea breath tests.

1 Marshall BJ, Goodwin CS, Warren RJ, et al. Prospective double-blind trial of duodenal ulcer relapse after eradication of Campylobacter pylori. Lancet 1988; ii: 1437-41.

2 Ferrero RL, Hazell SL, Lee A. The urease enzymes of Campylobacter pylori and a related bacterium. 7 Med Microbiol 1988; 27: 33-40.

3 Mobley HLT, Cotesia MJ, Resenthal LE, Jones BD. Characterisation of urease from Campylobacter pylori. $f$ Clin Microbiol 1988; 26: 831-6.

4 Marshall BJ, Warren JR, Francis GJ, Langton S, Goodwin CS, Blincow ED. Rapid urease test in the management of Campylobacter pyloridis associated gastritis. Am $\mathcal{J}$ Gastroenterol 1987; 82: 200-10.

5 Bell GD, Weil J, Harrison G. ${ }^{1+} \mathrm{C}$ urea breath analysis, a noninvasive test for Campylobacter pylori in the stomach. Lancet 1987; i: $1367-8$.

6 Marshall BJ, Surveyor I. Carbon- ${ }^{-1+}$ urea breath test for the diagnosis of Campylobacter pylori associated gastritis. $7 \mathrm{Nucl}$ Med 1988; 29: 11-6.

7 Graham DY, Klein PD, Evans DJ, Evans DG, Alpert LC, Opekun AR, et al. Campylobacter pylori detected noninvasively by the ${ }^{13} \mathrm{C}$-urea breath test. Lancet 1987; i: invasively

8 Mossberg SM, Thayer WR Jr, Spiro HM. Azotaemia and gastric acidity: the effect of intravenous urea on gastric acid and gastric ammonium production in man. $\mathcal{F}$ Lab Clin Med 1963; 61: 469-75

9 Chittajallu RS, Neithercut WD, Macdonald AMI, McColl KEL. Effect of increasing Helicobacter pylori ammonia production by urea infusion on plasma gastrin concentrations. Gut 1991; 32: 21-4.

10 Rauws EAJ, Langenberg W, Houthoff $\mathrm{HJ}$, Zanen HC, Tytgat GNJ. Campylobacter pyloridis-associated chronic acute antral gastritis. Gastroenterology 1988; 94: 33-40.

11 Weil J, Bell GD. Detection of Campylobacter pylori by the ${ }^{1+} \mathrm{C}$ breath test. In: Campylobacter pvlori and gastroduodenal disease. Rathbone BJ, Heatley RV, eds. London: Blackwell Scientific, 1989: 83-93. 